\title{
European Climate Services
}

\author{
Carlo Buontempo
}

\begin{abstract}
The launch of the Global Framework for Climate Services (GFCS, Hewitt et al., Nature Climate Change 2(12): 831-832, 2012) just a few years ago helped to redirect the focus of the climate community towards the users and their information needs. A number of national and international initiatives such as the Climate Service Partnership, or the Climate Science for Services Partnership between China and the UK, were designed to build upon such an international framework. The role of the European Commission appears to be very prominent in the international climate services landscape as it supported a largenumber of research and innovation programmes in the field. The chapter discusses the role climate services could play for the energy sector starting from an analysis of the interactions that already exist and building upon a few specific examples that indicate some good practice in climate service development.
\end{abstract}

Keywords Climate services $\bullet$ Climate risk management $\bullet$ Copernicus climate change service $\bullet$ Climate information - Strategic investment Energy trading

C. Buontempo $(\bowtie)$

European Centre for Medium-Range Weather Forecasts (ECMWF), Reading, UK

(C) The Author(s) 2018

A. Troccoli (ed.), Weather \& Climate Services for the Energy Industry, https://doi.org/10.1007/978-3-319-68418-5_3 


\section{INTRODUCTION}

One of the characteristics that distinguishes science from services is the centrality of the users. Independent of the specific sector of application, the identification of users' needs is at the same time a complex and fundamental operation in climate service development (cf. Lemos and Morehouse 2005). The complexity of such a critical step is made even more complex by the loose understanding among users of what is and what is not within the scope of climate services (Lourenço et al. 2015).

What is clear is that before trying to identify their needs it is essential to identify who the users are. From a climate service perspective, a user is a person whose actions (e.g. decisions, policies) are likely to be influenced by the provision of a specific set of climate information. Such a definition makes it clear that a user is an individual operating in a specific environment rather than an organisation or a sector. This is quite different from having an industrial stakeholder within a research project. A stakeholder could represent the needs of an industrial sector, but it may not necessarily have an immediate decision to take. For a climate service provider a good connection with a company or a public administration can represent a necessary rather than a sufficient condition for the identification of a user.

The existence of a powerful public narrative around global warming and climate change (Lowe et al. 2006) can make the identification of the suitable decision-making person within the target organisation more complex rather than simpler. Especially the energy sector where the connection between climate change and energy production is extremely strong, it can be challenging to keep separate the discussion about the impact that climate variability and climate change could have on the business from the longer-term strategy of the company. The identification of a suitable decision-maker within the target organisation often represents one of the first challenges the development of climate service for the energy industry faces. This means that a direct contact between climate service providers and users is not common especially during the initial phase of development of a new service.

More generally, the simplistic model that sees a provider of climate information meeting a decision-maker and developing for them a welldefined service does not represent the norm. Whilst the user-provider connection can be more or less convoluted, in most cases it involves one or more intermediaries who transform a user-relevant but still general climate information into a product or a service which meets the requirements of a specific user. 
What is critical to the success of the service is the ability to efficiently exchange information in both directions as user requirement can justify fundamental climate science development and users can see new opportunities once made aware of what the technology could currently achieve. A prerequisite for the development of a successful climate service is the establishment of a climate of mutual trust among all people involved (Brooks 2013).

Such a trust-building phase is necessary for a number of reasons. On the one hand, confidentiality issues can prevent industries from sharing specific requirements or operational practices in the open; on the other, a certain level of trust in the provider is required for users to consider the adoption of a specific service. Whilst it is at times possible to define sectorwide requirements such an assessment should be based on a generalisation of a series of user-specific requirements rather than a set of sector-wide requests which would otherwise be too loose and ill-defined to be actionable and acted upon. For example, whilst the energy sector as a whole may be interested in seasonal predictions of wind speed only, some specific professionals within the industry will use this information to inform specific decisions and they may require specific products (e.g. capacity factors at hub height or potential wind speed rather than $10 \mathrm{~m}$ wind speed as extracted from the models).

\section{Energy Users' Requirements for Climate Services}

Extrapolating from the experience acquired through EUPORIAS, a climate service project funded by the European Commission through its seventh framework programme (Hewitt et al. 2013), and the Copernicus Climate Change Service (C3S) ${ }^{1}$, we can tentatively identify some general requirements that emerge from energy users. In general terms, climate information is currently used to manage environmental risks and to plan maintenance to critical infrastructure. Climate data is also one of the key inputs considered by energy traders. On the longer time horizon climate information also represents one of many inputs into strategic investment decisions. Figure 3.1 gives a schematic overview of these aspects which are presented in some detail in the following sections.

\section{Climate Risk Assessment}

From the dry soil conditions which can affect the heating dissipation (and thus the rating) of underground cables (Stern et al. 2003) to the wind, ice 


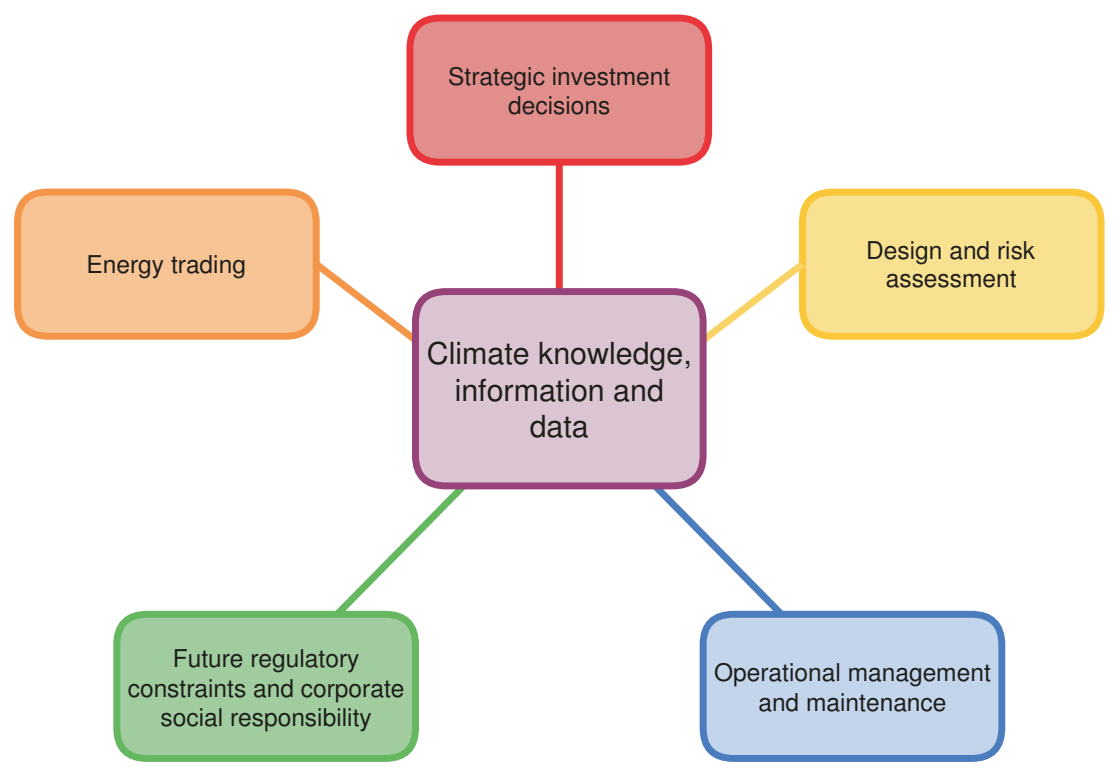

Fig. 3.1 A schematic representation of the ways in which climate information can be used within the energy sector

and snow storms which have crashed to the ground high-voltage transmission lines (Ward 2013; Campbell 2012), some of the aspects that have more directly affected the energy industry are directly related to the occurrence of isolated extreme climatic events or combination thereof.

In that sense, it is not surprising that one of the most common requests for climate information from Transmission Service Operators (TSOs) is related to climatological values (intensity and return periods) of extreme events in a changing climate. Civil and electrical engineers have built their practices on the assumption that the past weather events could provide a good guidance on the level of risk a specific infrastructure is likely to be exposed to. This is a solid approach in a world where the assumption of a stationary climate holds true, but it can become suboptimal if not even dangerous in a world characterised by a large, low-frequency climate variability and/or by a long-term trend in the parameters describing the statistical distribution of these variables (Wilby 2007). In general, long-lasting infrastructure requiring substantial investment is likely to be susceptible to a redefinition of building standards. However, in the energy sector, the 
expectations over such infrastructure are even higher given the impact and consequences that a failure in some of these systems may cause to society. For example, in the UK a nuclear power plant needs to be built so that it can withstand a 1 in 10,000-year return period flooding event (Starr 1981). It is thus clear that the analysis of environmental risks in a changing climate can become particularly complex for the energy sector (Rothstein and Parey 2011).

\section{Strategic Planning}

The second area of focus relates to the strategic planning of critical infrastructure. Traditionally, climate has not played a particularly big role in this kind of decisions, but the rapidity of the climatic changes and our growing capacity to predict some of them mean that this information is now playing a much more prominent role (Arnell and Delaney 2006; Larsen et al. 2008). For example, the viability of drilling and refining operations around the Caspian Sea (Zonn 2005) or the Persian Gulf will depend on a combination of freshwater availability, sea level rise and maximum daily temperature. Similarly, an investment decision in Floating Production, Storage and Offloading (FPSO) platform may be affected by the predicted change in wave conditions in the area as this can directly affect its design and ultimately the cost and possibly the return on investment of the infrastructure (Fonseca et al. 2010; Zou et al. 2014). Similarly, information on sea level rise or storminess could have a direct impact on the decision of decommissioning or not an offshore drilling platform (Burkett 2011).

In general, with the exception of renewable energy, climate information plays a relatively minor role in these strategic investment decisions. In fact, the economic, political and regulatory environment is likely to have more weight on the overall strategy that is adopted. A number of methodologies have been proposed to account for climate change and its associated uncertainty in investment decisions (Hallegatte et al. 2012; Lemos and Rood 2010) and an increase in the relative importance of climate information in strategic decisions in the years to come could be expected.

\section{Corporate Governance, Planning and Communication}

A recent analysis commissioned by the C3S through a contract led by the University of Reading has showed that one of the areas in which climate services are most used at the moment across all sectors is related to corporate 
governance and planning. Whilst the large uncertainty that comes with climate projections has often been identified as a barrier to the use of this information in strategic planning, having general indications, albeit uncertain, about what the future may hold appears to have a great relevance for corporate strategic planning. This appears to be particularly true for the energy sector possibly because of the direct link that exists between climate variability, climate change and energy. Given that legislation, public incentives and regulations have the power to affect the energy market significantly (e.g. Saidur et al. 2010), climate information could also be used by the industry to improve their understanding of how the regulatory framework may evolve in the years to come in response to societal pressure. For this kind of strategic decisions, information about mitigation strategies and carbon emissions are likely to be more relevant than the evaluation of climate change impacts. For example, having information about the likelihood to contain the global temperature change within 2 degrees from pre-industrial can have a significant bearing on the decarbonisation strategy the legislator is likely to pursue.

\section{Operation and Management}

The situation is rather different when looking at shorter timescales. Without necessarily entering the realm of weather predictions, it is clear that both historical climate and more recently climate predictions could be used to inform management decisions and operations (Troccoli 2010; Doblas-Reyes et al. 2013). This is of particular importance in a context where the fraction of renewable energy in the energy mix increases over time. Different from the traditional energy mix where climate represents simply an external factor, in the context of renewable energy the climate often represents the valuable asset itself. For example, planning the maintenance of an offshore wind farm can be an expensive operation which requires careful planning. Scheduling such a maintenance during a period characterised by relatively low wind conditions could both reduce the direct costs and reduce the loss in wind-energy production, as the turbine needs to be shut down during these operations. It is also becoming apparent that information about near-future conditions can provide useful insights into the return on investment. The 2015 wind drought in the USA has taken a lot of the industry by surprise and has impacted significantly the business plans of some of the operators. Although there is still some debate on the exact drivers of the drought, there is also evidence that it would have been possible to predict at least part of the observed wind anomalies. 


\section{Trading}

Given its peculiarity in terms of climate information, energy trading deserves a category on its own. The highly interconnected nature of the European energy and the geographical disparities in terms of energy demand and production represent a good base for the energy trading in the old continent. As in any market, the operators tend to pay attention to as many different pieces of relevant information as possible. Given that both energy demand and (to a greater extent) energy production depend on weather conditions, it is natural that traders have always shown a great deal of interest in meteorological information. Very short-term (e.g. $0-48$ hours) predictions, which are of greatest interest to traders, are now solidly in the hands of statistical post-processing algorithms (Foley et al. 2012). The trader forecasters are looking with growing interests at the predictions for the coming weeks and months as they feel that on those sorts of timescales their instinct and knowledge can still outperform the statistical tools and provide useful guidance for the traders.

The impact seasonal predictions have on the global gas market (Changnon et al. 1999) is an example of that and also shows how the market value of the predictions can often exceed the value climatologists would assign to it. Predicting something that is likely to affect the market is valuable per se even when the prediction itself turns out to be incorrect.

\section{Good Practice in Climate Services Development, FOR ENERGY AND BEYOND}

One of the outstanding challenges of climate service development is related to the balance between user relevance/drive and public development. In Europe, where the European Commission has been investing heavily on climate services through both research programmes and innovation actions (Street et al. 2015), the challenge is becoming quite evident. On the one hand, developing a service without sufficient user engagement could lead to a product which is much closer to the providers' perception of the users' needs rather than something that is actually fit for purpose. On the other hand, publicly funding a service that only addresses the need of a specific user is also not in the interest of the taxpayer and it is almost certainly not politically viable. An example of the tension that may exist between these two opposing situations is provided by EUPORIAS. The project, structured around six climate service 
prototypes, focused on the climate prediction timescale. At least two of the prototypes were directly relevant to the energy sector: Hydrological Seasonal Forecast System (HSFS) to support spring flood regulation planning, which provides seasonal forecasts of the spring flood onset and volume (1-5 months ahead) in support of hydropower reservoir regulation planning in Sweden, and RESILIENCE, a user-friendly tool to produce information of the future wind power resources based on probabilistic climate predictions. In the case of HSFS, the prototype was entirely funded by Energiforsk, the Energy Research Institute of Sweden, which was also the target user for the service. It was also clear for which specific basin the prototype was going to provide information. In the case of RESILIENCE, the project team went through a series of stages to identify the target users.

Figure 3.2 provides a snapshot of the award-winning ${ }^{2}$ graphical user interface they developed called project Ukko. ${ }^{3}$ The development of such visualisation, which represented the graphical user interface to the data generated within the RESILIENCE prototype of EUPORIAS, also provides a good example of the kind of tension that may arise during the development of a climate services. The tension was in this case between EUPORIAS management team who were keen to develop a very targeted product addressing the need of a specific user (e.g. the manager of a wind farm) and the project team who were keen to develop a generic platform able to serve with relatively little modification a variety of users. On the one hand, there was the intention to understand how much the tailoring could add to the usefulness of a service. On the other hand, there was the cost-effectiveness requirement to invest in a system that could be reused for other applications. There is no reason to believe that this kind of tension, which ultimately represents a design challenge, might be a general issue of climate service development.

\section{Opportunities for Climate Services, for Energy and Beyond}

The Copernicus programme, previously known as Global Monitoring for Environment and Security (GMES), is a European system for monitoring the Earth System. It consists of a number of platforms which collect, process and distribute data from multiple sources such as satellite and in situ sensors. Both elaborated and raw data provide users with reliable and upto-date information through a set of services, which address six thematic areas: land, marine, atmosphere, climate change, emergency management 


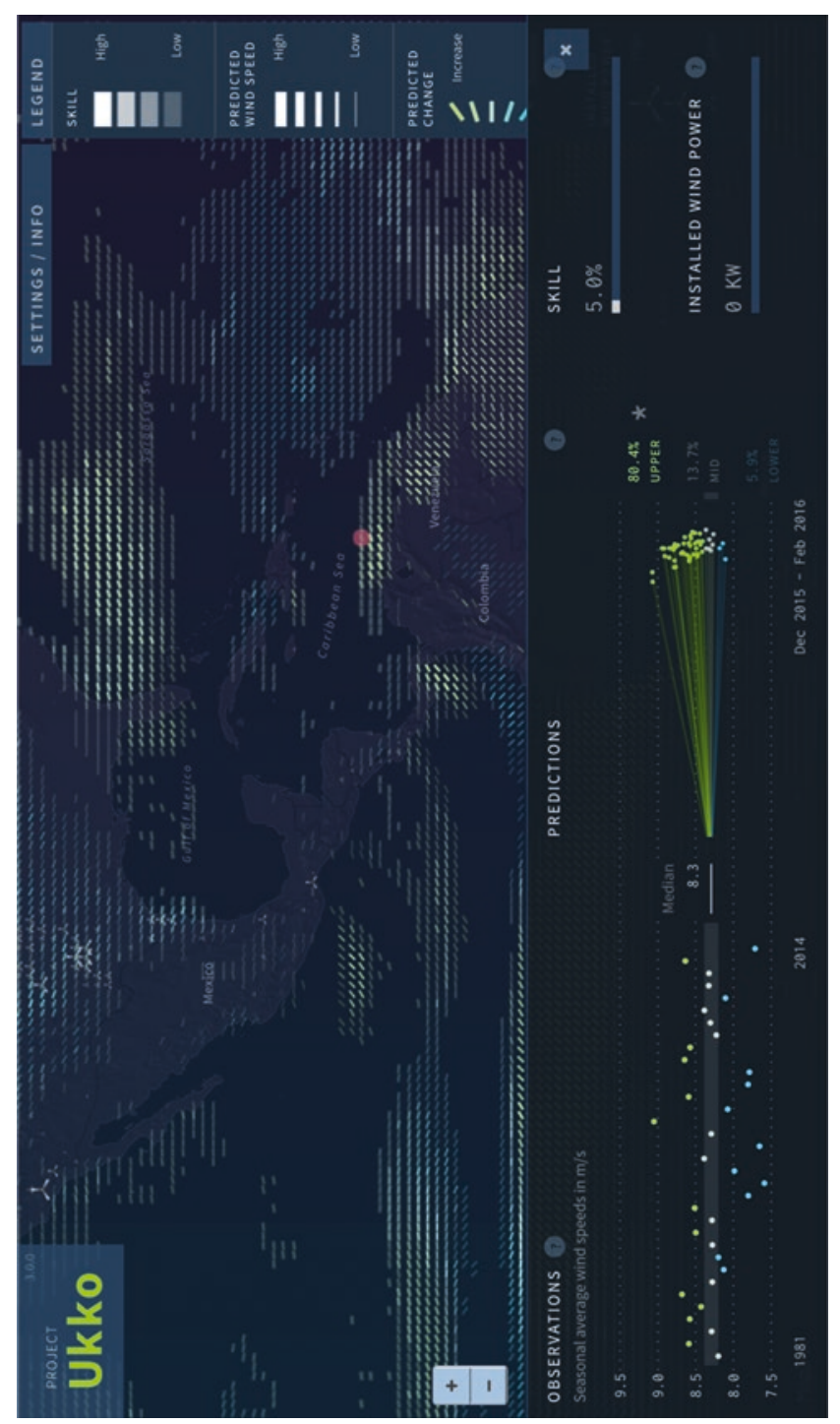

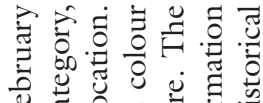

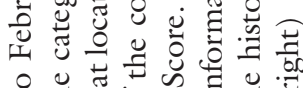

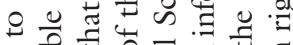

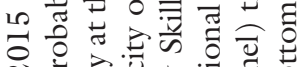

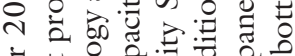
㐫 ี 过记 ป च

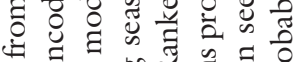

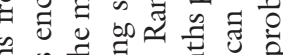
क ज $\exists$ च

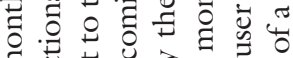
छ \& : Iี

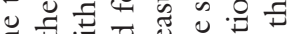
I อั ฮ $+\approx$ U d च

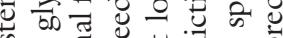

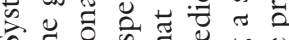
क I क क

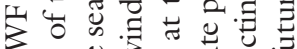

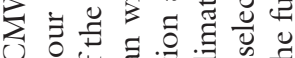

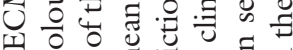
ี $\Xi$ : ฮี

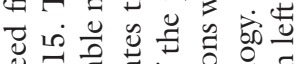

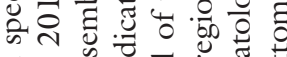

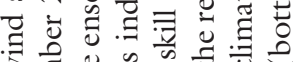
न है

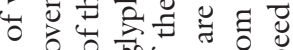
मे 0 का ป

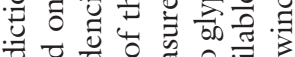

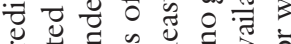

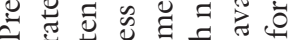

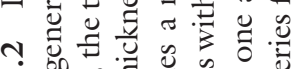
กั ம0

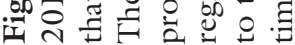


and security. The C3S, which is being implemented by the European Centre for Medium-Range Weather Forecast, is providing information for monitoring the global climate and predicting its evolution and will, therefore, help to support adaptation and mitigation efforts. The service will be built upon networks of in situ and satellite-based observations, re-analysis, seasonal predictions and climate projections. C3S will provide free and unrestricted access to several climate indicators and climate indices for both the historical and the future period.

The central piece of the C3S structure is the Climate Data Store, https://www.ecmwf.int/en/newsletter/151/meteorology/climateservice-develops-user-friendly-data-store. Despite its name, this is much more than a store of data as it represents a standardised access point to datasets (both those that exist already and the newly developed one) as well as a place where new application-relevant data will be made available. The data will include past observations and reconstructions, regional and global re-analysis, climate predictions and regional and global climate projections. The data will come with a standard set of tools which will allow users to define and then apply a range of post-processing procedures prior to the download of the data or graphics material they might need.

Alongside the development of the CDS, C3S is also developing a number of other important functions such as an Evaluation and Quality Control (EQC) — which will first define and then implement quality control procedures for all the dataset that will be made available by the C3Sand an Outreach and Dissemination (OD) function-which will be responsible for both training the users and the intermediaries and maintaining a support for the products and datasets.

One of the key aims of the C3S programme is to instigate the development of a market of climate services which could be built upon the free and unrestricted data policy of Copernicus. Although data accessibility is key to this vision, data on its own may not suffice for the uptake of climate information and data by users. To address this, the C3S is also developing a Sectoral Information System. This sub-programme is funding the development and the delivery of proof-of-concept demonstration services addressing the needs of specific sectors and users. The aim is to promote the development of conditions that will enable the use of the climate information provided rather than supporting a fleet of services for the end-users. Of the seven projects funded to date (Autumn 2016), two are designed to develop tools and datasets for the energy sector.

The first C3S Energy contract (European Climatic Energy Mixes, $\mathrm{ECEM}^{4}$ ), coordinated by the University of East Anglia, is looking at how 
different energy mixes will be able to meet demand on timescales ranging from the next season to the next decades in Europe. The main target of this C3S project is the development of an online interactive tool that will allow users to assess how energy production and demand will change in response to climatic factors in a specified region of Europe on different time horizons. This project, which at the time of writing is half-way through its completion, has already managed to identify a set of important technical developments that need to take place in order for the energy sector to be properly served. In addition, it has already provided their target users with something tangible they can play with: web-based demonstrator with up-to-date information about energy production and demand. Having a concrete tool to interact with is a fundamental step in the assessment of users' requirements.

The second C3S contract for the energy sector $\left(\right.$ CLIM4ENERGY ${ }^{5}$ ) is coordinated by the Commissariat á l'Énergie Atomique et aux énergies alternatives (CEA) and is expected to deliver nine energy-relevant pan-European indicators of climate trends and variability with cross-sectoral consistency, something that we believe will help users assess how exposed to climate extremes their infrastructure is likely to become in the coming decades.

Whilst none of these initiatives in isolation will be able to equip the energy sector with all the tools it needs for the challenges it is likely to face, these prototype service and demonstrators will provide useful examples for others to build upon. The recent adoption of Energy as a priority sector for the GFCS of the World Meteorological Organisation (WMO) means there is a general framework in which these experiences can be accounted for (WMO 2017).

Acknowledgement Project Ukko is a Future Everything and BSC project for EUPORIAS. Data visualisation by Moritz Stefaner. EUPORIAS is a project funded by the EU 7th Framework Programme (GA 308291) and led by the Met Office.

\section{Notes}

1. http://climate.copernicus.eu/.

2. Project UKKO received the silver prize for the Kantar Information Is Beautiful Award http://www.informationisbeautifulawards.com/news/ 188-2016-the-winners.

3. http://www.project-ukko.net.

4. http://ecem.climate.copernicus.eu/.

5. http://clim4energy.climate.copernicus.eu/. 


\section{REFERENCES}

Arnell, N. W., \& Delaney, E. K. (2006). Adapting to climate change: Public water supply in England and Wales. Climatic Change, 78, 227-255.

Brooks, M. S. (2013). Accelerating innovation in climate services: The 3 E's for climate service providers. Bulletin of the American Meteorological Society, 94(6), 807-819.

Burkett, V. (2011). Global climate change implications for coastal and offshore oil and gas development. Energy Policy, 39(12), 7719-7725.

Campbell, R. J. (2012). Weather-related power outages and electric system resiliency. Washington, DC: Congressional Research Service, Library of Congress.

Changnon, D., et al. (1999). Interactions with a weather-sensitive decision maker: A case study incorporating ENSO information into a strategy for purchasing natural gas. Bulletin of the American Meteorological Society, 80(6), 1117-1125.

Doblas-Reyes, F. J., et al. (2013). Seasonal climate predictability and forecasting: Status and prospects. Wiley Interdisciplinary Reviews: Climate Change, 4(4), $245-268$.

Foley, A. M., et al. (2012). Current methods and advances in forecasting of wind power generation. Renewable Energy, 37(1), 1-8.

Fonseca, N., et al. (2010). Numerical and experimental analysis of extreme wave induced vertical bending moments on a FPSO. Applied Ocean Research, 32(4), 374-390.

Hallegatte, S., et al. (2012). Investment decision making under deep uncertainty application to climate change. World Bank Policy Research Working Paper 6193. Washington, DC: World Bank.

Hewitt, C., Mason, S., \& Walland, D. (2012). The global framework for climate services. Nature Climate Change, 2(12), 831-832.

Hewitt, C., Buontempo, C., \& Newton, P. (2013). Using climate Predictions to better serve society's needs. Eos, Transactions American Geophysical Union, 94(11), 105-107.

Larsen, P. H., et al. (2008). Estimating future costs for Alaska public infrastructure at risk from climate change. Global Environmental Change, 18(3), 442-457.

Lemos, M. C., \& Morehouse, B. J. (2005). The co-production of science and policy in integrated climate assessments. Global Environmental Change, 15(1), 57-68. ISSN: 0959-3780. https://doi.org/10.1016/j.gloenvcha.2004.09.004. Retrieved from http://www.sciencedirect.com/science/article/pii/S0959378004000652

Lemos, M. C., \& Rood, R. B. (2010). Climate projections and their impact on policy and practice. Wiley Interdisciplinary Reviews: Climate Change, I(5), 670-682. 
Lourenço, T. C., et al. (2015). The rise of demand-driven climate services. Nature Climate Change, 6, 13-14.

Lowe, T., et al. (2006). Does tomorrow ever come? Disaster narrative and public perceptions of climate change. Public Understanding of Science, 15(4), $435-457$.

Rothstein, B., \& Parey, S. (2011). Impacts of and adaptation to climate change in the electricity sector in Germany and France. Climate Change Adaptation in Developed Nations, 231-24l (Springer Netherlands).

Saidur, R., et al. (2010). A review on global wind energy policy. Renewable and Sustainable Energy Reviews, 14(7), 1744-1762.

Starr, C. (1981). Risk criteria for nuclear power plants: A pragmatic proposal ${ }^{1}$. Risk Analysis, 1, 113-120. https://doi.org/10.1111/j.1539-6924.1981. tb01406.x.

Stern, E., Newlove, L., \& Svedin, L. (2003, January 1). Auckland unplugged: Coping with critical infrastructure failure. Lanham, MD: Lexington Books. ISBN: 9780739107744.

Street, R., et al. (2015). A European research and innovation roadmap for climate services. European Commission, 702151. ISBN: 978-92-79-44341-1. https:// doi.org/10.2777/702151.

Troccoli, A., Boulahya, M. S., Dutton, J. A., Furlow, J., Gurney, R. J., \& Harrison, M. (2010). Weather and climate risk management in the energy sector. Bulletin of the American Meteorological Society, 6, 785-788. https://doi.org/10.1175/ 2010Bams2849.1.

Ward, D. M. (2013). Climatic Change, 121, 103. https://doi.org/10.1007/ s10584-013-0916-z.

Wilby, R. L. (2007). A review of climate change impacts on the built environment. Built Environment, 33(1), 31-45.

WMO. (2017). Energy exemplar to the user interface platform of the global framework for climate services. World Meteorological Organisation, $120 \mathrm{pp}$. Retrieved from https://library.wmo.int/opac/doc_num.php?explnum_id=3581

Zonn, I. S. (2005). Environmental issues of the Caspian. The Caspian sea environment (pp. 223-242). Berlin; Heidelberg: Springer.

Zou, T., Jiang, X., \& Kaminski, M. L. (2014). Possible solutions for climate change impact on fatigue assessment of floating structures. The Twenty-fourth International Ocean and Polar Engineering Conference. International Society of Offshore and Polar Engineers. 
Open Access This chapter is distributed under the terms of the Creative Commons Attribution 4.0 International License (http://creativecommons.org/ licenses/by/4.0/), which permits use, duplication, adaptation, distribution and reproduction in any medium or format, as long as you give appropriate credit to the original author(s) and the source, a link is provided to the Creative Commons license and any changes made are indicated.

The images or other third party material in this chapter are included in the work's Creative Commons license, unless indicated otherwise in the credit line; if such material is not included in the work's Creative Commons license and the respective action is not permitted by statutory regulation, users will need to obtain permission from the license holder to duplicate, adapt or reproduce the material. 